\title{
Clinico-histopathological correlation of skin biopsies in leprosy
}

\author{
Manandhar $\mathrm{U}^{1}$, Adhikari RC ${ }^{2}$, Sayami G \\ ${ }^{I}$ Department of Pathology, Nepal Medical College, Jorpati, Attarkhel, Kathmandu, Nepal \\ ${ }^{2}$ Department of Pathology, Institute of Medicine, Tribhuwan University Teaching Hospital, Kathmandu, Nepal
}

\section{Keywords: \\ Granulomatous skin lesion; \\ Leprosy; \\ Skin biopsy}

\begin{abstract}
Background: In leprosy, there is a range of varied clinicopathologic manifestations and the diagnosis is made from adequate clinical information combined with bacilloscopy and histopathology which helps in diagnosing different types of leprosy and separating it from other granulomatous lesions. Aim of the study was to classify leprosy according to Ridley Jopling classification and perform the clinicopathological correlation.
\end{abstract}

Materials and Methods: A cross sectional comparative study of skin biopsies of newly diagnosed leprosy recieved over a period of 18 months from January 2009 to June 2010 and clinicopathologic correlation was done along with special stain.

Results: This study included 75 patients diagnosed clinically as leprosy. Skin biopsy revealed evidence of leprosy in 72 cases. Maximum number of patient clinically belonged to tuberculoid leprosy which constituted $25(33 \%)$ cases followed by borderline tuberculoid $19(25.33 \%)$. On the contrary, histologically borderline tuberculoid was the most common type $(40 \%, \mathrm{n}=30)$ cases and tuberculoid leprosy constituted $(13.33 \%, \mathrm{n}=10)$ cases. Three cases of clinically diagnosed tuberculoid leprosy showed no features of leprosy histologically. Clinical and histopathological correlation was seen in 34 cases $(45.33 \%)$. The correlation was highest in borderline tuberculoid (63.15\%) followed by borderline lepromatous and lepromatous leprosy. Slit skin smear was positive in 31 cases $(43.05 \%)$. Fite Farraco stain was positive in 18 cases $(25 \%)$.

Conclusion: The classification of leprosy requires attention to the histopathological criteria and correlation with clinicalinformationand bacteriological examination so as to facilitate accurate therapy to prevent undesirable complication.

\section{INTRODUCTION}

Leprosy, Hansen's disease, is a chronic granulomatous infectious disease caused by Mycobacterium leprae. It is a

\section{Correspondence:}

Dr. Usha Manandhar, MD

Lecturer, Department of Pathology, Nepal Medical College and Teaching

Hospital, Jorpati, Attarkhel, Kathmandu, Nepal

Email: ushamanandhar08@gmail.com slowly progressive, chronic infectious disease which mainly affects peripheral nerve and skin which can express itself in different clinicopathological forms depending on immune status of host. ${ }^{1}$

Depending on degree of immunity, clinical and histopathological features various types of leprosy gradually may develop. ${ }^{2}$ Histopathological examination of skin or nerve biopsies and demonstration of acid fast bacilli 
in histopathological section and in slit skin smear aid in diagnosis of leprosy. ${ }^{3}$

Most cases of leprosy can be diagnosed without histopathological examination. Examination of a biopsy specimen for histopathology can be valuable aid to reach confirmatory diagnosis and its subtypes, differential diagnosis and prognosis of the disease and assessment or regression of the disease in patient under treatment and also for research. ${ }^{4,5}$

But biopsy has its limitation; it cannot provide definitive diagnosis, in cases like tuberculoid and indeterminate types. There should be close interaction between pathologist and clinician for understanding the disease and for benefit of the patient. $^{6}$

Along with provided detailed clinical information and bacilloscopic examination, skin biopsies play an important role in separating from other causes of granulomatous lesions. $^{7}$

Diagnosis of leprosy is based on different clinical parameters which involve detailed examination of skin lesion and peripheral nerve and skin smear examination. ${ }^{8}$ In some early and borderline cases of leprosy, it is difficult to diagnose only on clinical basis, hence histopathological examination is a must for confirmation of diagnosis in doubtful cases of leprosy. Clinico-histopathological correlation of leprosy assumes a pivotal role for early diagnosis. ${ }^{2}$ If disparity is observed, more advanced findings (that is towards lepromatous pole) should be given more weightage and it is classified and treated accordingly to prevent inadequate treatment. ${ }^{4}$

Ridley and Jopling laid down precise criteria for histological typing of leprosy. However, results of different studies have not been uniform and noted disparity between the clinical and histological diagnosis.

Due to potential neural damage and consequent disabilities and stigma of leprosy for human, correct histopathological diagnosis is mandatory. Present study had been conducted for clinical and histopathological correlation of skin biopsy to arrive at a definitive diagnosis of leprosy and to classify the types of disease. The aim of this study was to correlate histopathological diagnosis of skin biopsies with clinical diagnosis of leprosy.

\section{MATERIALS AND METHODS}

This is hospital based, cross-sectional comparative study of 75 cases conducted at department of pathology, Institute of Medicine, Tribhuvan University Teaching Hospital, Kathmandu, Nepal over a period of 18 months from Janaury 2009 to June 2010. Punch biopsies were taken from clinically newly diagnosed new skin lesion of leprosy patient and stained by Hematoxylin-Eosin (HE) and Fite Faraco stain. History and clinical examinations of patient regarding location of skin lesion, type of skin lesion and slit skin smear (SSS) stained with Ziehl-Neelsen stain were recorded. Clinical classifications of leprosy done by dermatologist were noted. Histopathological classification of leprosy was done according to Ridley and Jopling classification. Statistical analysis was done using SPSS 16.0 .

\section{RESULTS}

Seventy five clinically diagnosed cases of leprosy were included in the study. Out of the 75 cases, skin biopsy showed evidence of leprosy in 72 cases. Three cases showed histologically no evidence of leprosy, diagnosed as superficial perivascular dermatitis. All these 3 cases were negative both in slit skin smear and Fite stain.

The age distribution of patients varied between 11-75 years. Majority of the patient were between the age groups of 2030 years followed by $60-70$ years. Among the total 72 cases 54 were male and 18 female with male to female ration 3:1.

The frequency of the cases was based on the histopathological diagnosis. Most common clinical type of leprosy was tuberculoid group of leprosy (fig.1).

Table 1: Clinico-histopathological correlation of leprosy

\begin{tabular}{|c|c|c|c|c|c|c|c|c|c|c|}
\hline \multicolumn{11}{|l|}{ Clinical diagnosis } \\
\hline Types of leprosy & No of pt & TT & BT & BB & $\mathrm{BL}$ & LL & IL & Superficial perivascular dematitis & Agreement & Percentage \\
\hline \multicolumn{11}{|l|}{$(\%)$} \\
\hline $\mathrm{TT}$ & 25 & 6 & 13 & & & & 3 & 3 & $6 / 25$ & 24 \\
\hline BT & 19 & 3 & 12 & 1 & 2 & & 1 & & $12 / 19$ & 63.15 \\
\hline BB & 1 & & 1 & & & & & & $0 / 1$ & 0.00 \\
\hline BL & 14 & 1 & 3 & 2 & 8 & & & & $8 / 14$ & 57.14 \\
\hline LL & 14 & & 1 & 1 & 4 & 8 & & & $8 / 14$ & 57.14 \\
\hline Histioid & 2 & & & & & 2 & & & $0 / 2$ & 0.00 \\
\hline IL & 0 & & & & & & & & & \\
\hline TOTAL & 75 & 10 & 30 & 4 & 14 & 10 & 4 & 3 & $34 / 75$ & 45.33 \\
\hline
\end{tabular}


Tuberculoid (TT) and borderline tuberculoid (BT) leprosy (fig.2) constituted 25 (33.33\%) and 19 (25.33\%) cases respectively followed by lepromatous group each constituting 14 (18.67\%) cases. Most common histological type of leprosy was borderline tuberculoid leprosy seen in $30(40 \%)$ cases followed by borderline lepromatous (BL) leprosy (fig.3) 14 (18.67\%) cases. Lepromatous group of leprosy (fig.4) was most predominant in male than in female.

Among 75 cases, 34 (45.33\%) cases showed good correlation between clinical and histopathological diagnosis. Maximum correlation was observed in borderline tuberculoid (63.15\%) and lepromatous groups (57.14\%). A poor correlation was seen in tuberculoid leprosy (24\%; Table1).

Maximum major disagreement (difference of two or more than two group e.g. TT- LL) was seen in borderline lepromatous leprosy (28.57\%). One out of 14 clinically diagnosed BL was classified as TT, three cases as borderline tuberculoid in histopathology.

Thirteen cases of TT showed minor disagreement (difference of one group e.g. TT- BT), classified as borderline tuberculoid and three cases showed indeterminate leprosy. Thirty nine percent cases of leprosy manifested with plaque followed by macule in $32 \%$ cases. The upper extremity was most common site of lesion (29\%). Twenty four percent of the lesions were seen in all over the body

All tuberculoid leprosy and indeterminate leprosy were negative in SSS and Fite stain. All ten cases of lepromatous leprosy showed positive SSS (fig.5) while Fite stain in biopsy were negative in two cases.

\section{DISCUSSION}

In the present study, Ridley-Jopling classification was used to classify leprosy histopathologically in all cases. Indeterminate (fig.6) and histioid types of leprosy were also included for analysis. Skin biopsy showed evidence of leprosy in 72 cases (96\%).

Most common age group affected in leprosy was 20-30 years followed by $60-70$ years. In a study done by Moorthy $\mathrm{BN}$ et
Table 2: Comparative study in clinico-pathological correlation by different authors.

\begin{tabular}{|c|c|c|}
\hline Various studies & $\begin{array}{l}\text { Number } \\
\text { of cases }\end{array}$ & $\begin{array}{c}\text { Clinicohistopathological } \\
\text { correlation( }(\%)\end{array}$ \\
\hline Present study, 2010 & 75 & 45.33 \\
\hline Sehgal $\mathrm{VN}$ et a $1^{17}$ & 95 & 33 \\
\hline Vargas-ocampo $\mathrm{F}$ et $\mathrm{al}^{7}$ & 6000 & 42.9 \\
\hline Mitra $\mathrm{K}$ et al ${ }^{4}$ & 2640 & 57.16 \\
\hline Pandya AN et al ${ }^{2}$ & 50 & 58 \\
\hline Moorthy $\mathrm{BN}$ et $\mathrm{al}^{9}$ & 372 & 62.63 \\
\hline Kalla $\mathrm{G}$ et $\mathrm{a}^{18}$ & 736 & 64.7 \\
\hline Ridley DS et $\mathrm{al}^{8}$ & 82 & 68.3 \\
\hline Jerath VP et al ${ }^{14}$ & 130 & 68.5 \\
\hline Bhatia AS et al $^{16}$ & 1272 & 69 \\
\hline Kar PK et al $1^{15}$ & 120 & 70 \\
\hline Nadkarni NS et al ${ }^{19}$ & 2640 & 81.8 \\
\hline
\end{tabular}

al, majority of patients were between 20-29 years (20.70\%). Children below 9 years were least affected $(6.45 \%) .{ }^{9}$ In our study also, youngest age affected was 11years. In one series, age range was 6-72 years and mean age was 35.9 years. ${ }^{10}$ In a another study done in Green Pasteur Hospital, Pokhara, the mean age was 41 years. ${ }^{11}$

In this study, male predilection was seen in $75 \%$ of cases. Different studies showed that leprosy was more prevalent in males than in females. ${ }^{12,13}$

Lepromatous group of leprosy were more common in male than in female, with male to female ratio (M:F) of 9:1 in LL and13:1 in BL. Tuberculoid group also showed slight male predominance with M:F ratio of 1.5:1 in TT and 2:1 in BT. Vargas-ocampo $\mathrm{F}$ et al. found that males were predominantly affected in lepromatous leprosy and tuberculoid leprosy was only form of leprosy more frequent in females than in males. ${ }^{6}$

Macules, nodules, plaque were the skin lesions most frequently biopsied. Most common skin lesions manifestation in leprosy in present study was plaque followed by macule. Macules found to be most common lesion in a study done by Vargas-ocampo F et al. ${ }^{6}$

Table 3:Comparative study of correlation in different histopathology types by different authors.

\begin{tabular}{c|c|c|c|c|c|c|c}
\hline $\begin{array}{c}\text { Types of } \\
\text { leprosy }\end{array}$ & $\begin{array}{c}\text { Jerath VP } \\
\text { et al }^{14}\end{array}$ & $\begin{array}{c}\text { Bhatia AS } \\
\text { et al }^{16}\end{array}$ & $\begin{array}{c}\text { Nadkarni NS } \\
\text { et al }^{19}\end{array}$ & $\begin{array}{c}\text { Kar PK } \\
\text { et al }^{15}\end{array}$ & $\begin{array}{c}\text { Kalla G } \\
\text { et al }^{18}\end{array}$ & $\begin{array}{c}\text { Moorthy BN } \\
\text { et al }^{9}\end{array}$ & $\begin{array}{c}\text { Present study } \\
\text { TT }\end{array}$ \\
\hline 74.5 & 50 & 97 & 87.5 & 76.7 & 46.15 & 24 \\
BT & 64.7 & 77 & 95 & 60.9 & 44.2 & 66.66 & 63.15 \\
BB & 53.8 & 25 & 89 & 54.5 & 37 & 50 & 0 \\
BL & 28.5 & 43 & 87 & 53.8 & 43.7 & 70 & 57.14 \\
LL & 61.5 & 91 & 98 & 71.4 & 75.6 & 80 & 57.14 \\
IL & 88.8 & 35 & & 81.2 & & 20 & 0
\end{tabular}




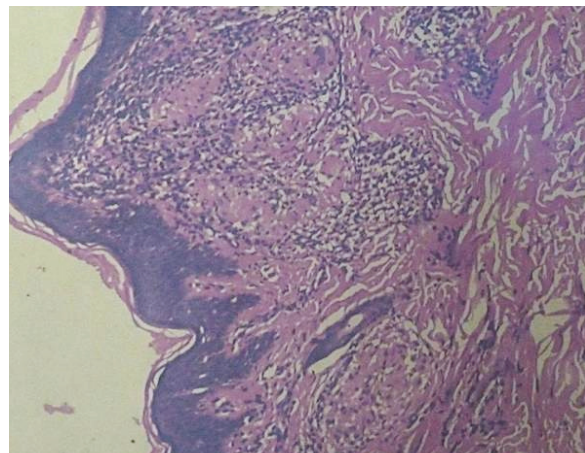

Figure 1: Tuberculoid leprosy: Erosion of basal layer of epidermis by lymphocytes and epithelioid cells without intervening clear zone. Multiple well-formed granulomas in papillary dermis (HE Stain, X100).

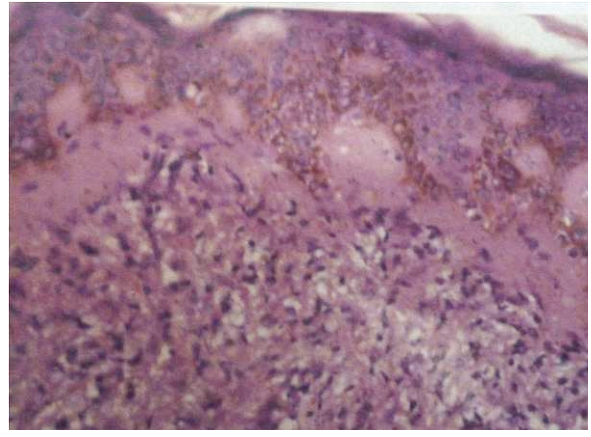

Figure 3: Boderline lepromatous leprosy. Grenz zone with foamy cells, epithelioid cells and lymphocytic infiltration (HE Stain, X400).

Since 1966, leprosy was classified by Ridley and Jopling into 5 subtypes (TT, BT, BB, BL, and LL) based on clinical, histopathological and immunological features and bacteriological findings has been widely adopted by histopathologist and leprologist. ${ }^{8}$ Despite having such an accurate classification, leprosy cases showed so many diversity between clinical and histopathological features.

The different clinical form through which leprosy manifests is accompanied by specific histopathological picture. Thus towards TT end of the spectrum, histopathology shows epithelioid cells, Langhans giant cells and lymphocytes and while towards LL end of spectrum, there are more foamy macrophages. ${ }^{8}$

According to this classification, in present study, the mostcommon clinical subtype was tuberculoid (25/75), followed by borderline tuberculoid (19/75). Histologically, the most common classification made was borderline tuberculoid (30/75) leprosy. Clinically none of the cases classified as indeterminate leprosy and histologically none of the cases showed histological features of histioid leprosy. Three out of 25 case of clinically diagnosed TT showed no evidence of leprosy in histopathology.

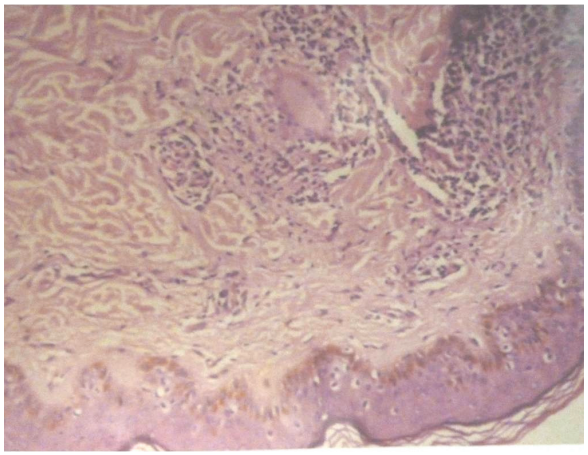

Figure 2: Boderlinetuberculoid: Clear subepidermal zone with well formedepithelioid cell granulomas and langhans giant cell (HE Stain, X200).

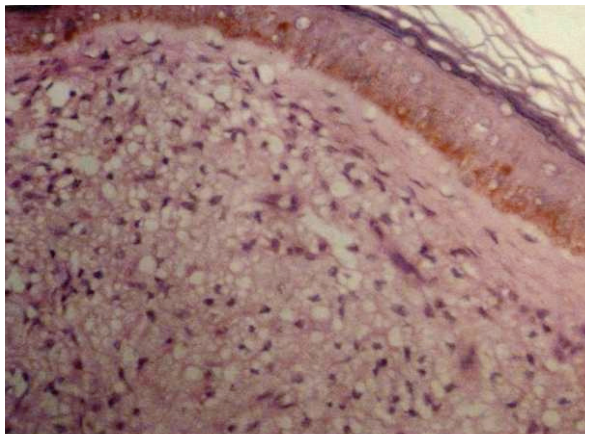

Figure 4: Lepromatous leprosy: Collection of foamy macrophages in the dermis with clear grenz zone under the epidermis (HE Stain, X400).

Moorthy BN et al, observed borderline tuberculoid (BT), as most common type of leprosy which constituted 269 cases and tuberculoid (TT) leprosy constituted 26 cases. $^{9}$

There was complete agreement between the clinical and histopathologic diagnosis in $45.33 \%$ of the cases. Differentiation between leprosy subtypes is sometimes difficult or impossible. So different studies were performed regarding clinico-histopathological correlation, and showed variable results. Percentage of complete agreement between clinical and histopathological diagnosis reported by different authors ranges from $33-82 \%$ (Table 2 ).

In the present study, positive clinico-histopathological correlation was better noted in BT and lepromatous group in comparison to TT. Different studies observed highest percentage of clinicopathological correlation of lepromatous leprosy and tuberculoid leprosy in their studies and showed least clinic-pathological correlation in midboderline lepomatous leprosy. The correlation was least in IL except in the study conducted by Jerath VP et al and Kar PK et al. ${ }^{14,15}$ Similarly, minimal correlation was seen in midboderline leprosy in a study done by Bhatia AS. ${ }^{16}$ In contrast to our study, Nayak SV et al study showed maximum correlation 


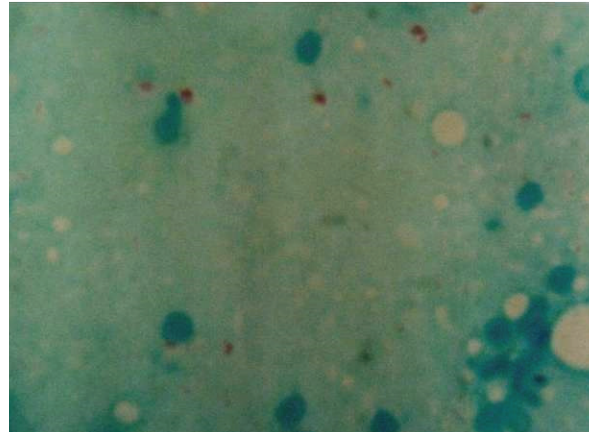

Figure 5: Mucinous carcinoma with multiloculatedcysts.

in midboderline (100\%) (Table 3$)^{3}$

Among the patients classified clinically as BT, three cases were TT and two cases were BL on histopathology. Out of 25 clinically diagnosed TT, 13 cases were classified as BT and three cases showed no evidence of leprosy, reported as superficial perivascular dermatitis.

Both BT and TT are only slightly different both clinically and histopathologically. Clinically, both of these cases manifested with well-defined lesions with partial or complete loss of sensation with or without thickened nerve and scant acid fast bacilli. Histologically, they present with similar granulomatous reaction, so there is difficulty in differentiating the TT and BT both clinically and histologically. The present criteria appears to be inadequate in differentiating these two. ${ }^{16}$

There was a minor disagreement of difference of one group in $29(38.66 \%)$ cases and major disagreement of difference of two or more groups in $9(12 \%)$ cases, while histology was nonspecific in three cases of clinically diagnosed tuberculoid leprosy (4\%). Ridley and Jopling, found minor disagreement in 21 patient (25.6\%), major disagreement in 5 patient $(6 \%){ }^{8}$

In present study, maximum major disagreement between clinical and histopathological diagnosis was observed in four $(28.57 \%)$ cases of borderline lepromatous leprosy. Three cases clinically diagnosed as BL leprosy were TT on histopathology and one case was classified as BT.

Three cases of TT and one case of BT showed histological features of indeterminate leprosy. Similarly, other authors also found features of indeterminate leprosy in clinically diagnosed tuberculoid group of leprosy., ${ }^{5,16,17}$ Many lepromatous and tuberculoid leprosy after treatment show indeterminate histopathological feature. ${ }^{4}$ One case of LL classified as BT leprosy and three cases of BL classified as BT leprosy. Similarly, a study done by Bhatia AS et al showed two cases of BL and three cases of LL as BT on histopathology. ${ }^{16}$ Sehgal VN et al. also showed one case of $\mathrm{BL}$ as $\mathrm{BT} .{ }^{17}$

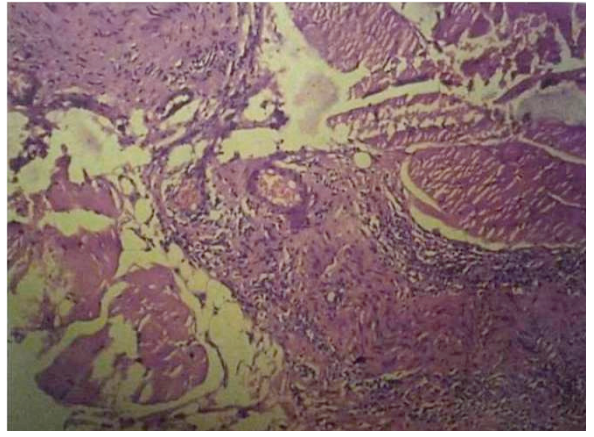

Figure 6: : Indeterminate leprosy: Deep dermal nerve enlarged and perineural lymphocytic infiltrations (HE Stain, X100).

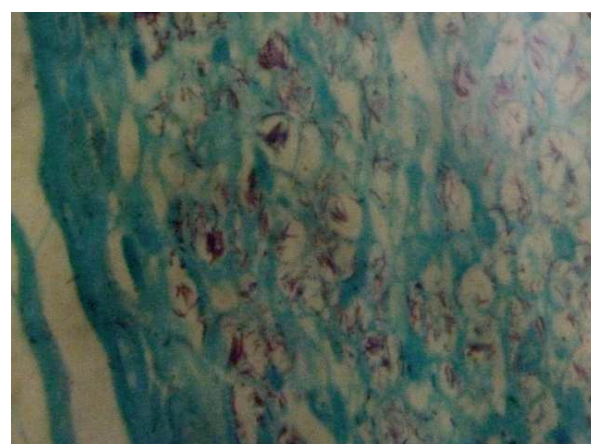

Figure 7: Lepromatous leprosy: Lepra bacilli extending towards epidermis (Fite stain, $\mathrm{X} 1000)$.

The discordance between clinical and histopathological diagnosis was noticed because clinical diagnosis was made on the lines of Ridley Jopling classification even when histopathological examination had not been done. Various factors influence the histopathological diagnosis, including different criteria used to select the cases, number of cases of each type, age of the lesion, nature and depth of the biopsy, quality of the section, number of acid-fast stained sections examined, immunological and treatment status of the patient at the time of diagnosis. If biopsy is taken at an early stage, discordance between clinical and histopathologic observation is more likely. There is also inter observer variation both clinically and histopathologically, so there could be overlap between different types of leprosy. ${ }^{16}$

The disparity could be due to the occurrence of reaction or due to type and site of lesion from where biopsy was taken. ${ }^{18}$ Selection of the site forbiopsy plays an important role in histopathological diagnosis since clinically dissimilar lesions biopsied from same patient can show different types of histopathology. ${ }^{19}$ Clinician must know proper selection of site and type of lesion for histological examination. ${ }^{6}$

It is very difficult even for experienced dermatologist and leprologist to diagnose early lesion of leprosy, so definitive diagnosis may be possible only by histopathological examination. ${ }^{16}$ The variable tissue response in the disease spectrum due to variability of CMI is responsible for the disparity in various types of leprosy, irrespective of the type 
of the lesions. ${ }^{20}$

Some degree of overlaps are seen between different types of leprosy both clinically and histopathologically and immunologically, correlation of clinical and histopathological features along with bacteriological index is more useful for accurate typing of leprosy than considering single parameter alone. ${ }^{9}$

In present study, Fite Faraco stain were positive for acid fast bacilli (AFB) in $18(25 \%)$ skin biopsies, detected in 9 with BL, 8 with LL (fig.7) and 1 in BB. None of the TT, BT, IL cases showed bacilli in Fite stain. Fite stain has little role if smears were with few or scant bacilli, they are likely to be missed. ${ }^{21}$ In study done by Bal A et al, lepra bacilli seen in 7 cases out of 206 BT patients and all cases of lepromatous group of leprosy demonstrated bacilli whereas none of the 27 TT were positive as in present study. ${ }^{22}$

The slit skin smears (SSS) were positive in $31(43.05 \%)$ cases. Among them; 13 were from BL and 10 from LL patients, while 3 were from BB and 5 from BT patients. All the smears were negative in tuberculoid and indeterminate leprosy patients. One case of borderline lepromatous leprosy was Fite stain positive and SSS negative for AFB.

In our study, slit skin smear significantly identified more number of positive cases than in Fite stain. 10 patients (3BB, 5BL, 2LL) had AFB in SSS but not in tissue sections.

However, in contrast to our study, various studies reported better demonstration of AFB in biopsy than in slit skin smear. ${ }^{23,24}$ Bhusan $\mathrm{P}$ et al. found significant number of positive cases in biopsy which constituted $65(46.09 \%)$ cases while SSS positive only in 43 (30.05\%) cases. Both SSS and Fite stain were negative in indeterminate and tuberculoid leprosy as in our study and they concluded that demonstration of bacilli in biopsy most sensitive and effective especially in pauci-lesional patient. ${ }^{23}$ AFB are better demonstrated in biopsies than in slit skin smear due to presence of AFB in deep reticular dermis where they remain inaccessible to SSS. ${ }^{25}$

In a study done by Bhusan $\mathrm{P}$ et al, 5 cases (3-BT, 1-BB, 1-LL ) were positive for AFB in slit skin smear but negative in biopsy. ${ }^{24}$ Groenen $\mathrm{G}$ et al. also reported $15 \%$ of cases were slit skin smear positive and Fite stain negative in tissue section. ${ }^{25}$ These bacilli in biopsies may be missed, if bacilli are concentrated in one specific area but biopsy slices do not include that area, especially in case of low density bacillary load and biopsy taken at the wrong spot. ${ }^{8}$

\section{CONCLUSION}

Histological examination of skin lesion is an important tool in the accurate classification of leprosy. Clinical diagnosis of early leprosy lesion offer difficulties hence biopsies should be done in all leprosy cases and to correlate biopsy results with those of clinical diagnosis in order to improve classification and prognosis. Correlation of clinical and histopathological features along with bacteriological index is more useful for accurate typing of leprosy than considering single parameter alone.

As there is overlap in histopathologic features of different types of leprosy, morphology alone is not specific, thus adequate clinical data can help in good clinicopathologic correlation.

\section{REFERENCES}

1. Walker SL, Lockwood DN. The clinical and immunological features of leprosy. Br Med Bull 2006;78:103-21.

2. Pandya AN, Tailor HJ. Clinocohistopathological correlation of leprosy. Ind J Dermatol Venerol Leprol 2008;74:174-6.

3. Nayak SV, Shivarudrappa AS, Nagarajapa AH, Sacchidanand S, Ahmed SM. Role of modified rapid AFB method in histopathological sections of hansen's disease. Ind J Dermatol Venereol Leprol 2003;69:173-4.

4. Mitra K, Biswas S, Saha B, Dasgupta A. Correlation between clinical and histopathological criteria for the classification of leprosy. Ind J Dermatol Venereol Leprol 2001;46:135-7.

5. Fite GL, Mansfield RE. The role of histopathology in the study of leprosy. Arch Dermatol 1969;100:478-83.

6. Vargas-ocampo F. Analysis of 6000 skin biopsies of the National leprosy control program in Mexico. Int J Lepr Other Mycobact Dis 2004;72:427-36.

7. Lucus SB, Ridley DS. The use of histopathology in leprosy diagnosis and research. Lepr Rev 1989;60:257-62.

8. Ridley DS, Jopling WH. Classification of leprosy according to immunity: A five group system. Int J Lepr Other Mycobact Dis 1966;34:255-73.

9. Moorthy BN, Kumar P, Chatura KR, Chandrasekhar HR, Basavaraja PK. Histopathological correlation of skin biopsies in leprosy. Ind J Dermatol Venereol Leprol 2001;67:299-301.

10. Robertson LM, Nicholls PG, Butlin CR. Delay in presentation and start of treatment in leprosy: experience in an out- patient clinic in Nepal. Lepr Rev 2000;71:511-6.

11. Van Brakel WH, Khawas IB, Lucas SB. Reaction in leprosy: an Epidemiological Study of 386 Patient in West Nepal. Lepr Rev 1994;65:190-203.

12. Palande DD, Bowden REM. Early detection of damage to nerves in leprosy. Lepr Rev 1992;63:60-72.

13. Britton WJ. Immunology of leprosy. Trans Roy Soc Trop Med Hyg 1993;82:508-14.

14. Jerath VP, Desai SR. Diversities in clinical and histopathological classification of leprosy. Leprosy in India 1982;54:130-4.

15. Kar PK, Arora PN, Ramasastry CV, Sayal SK, Dhaka RS. Clinicopathological study of macular lesions in leprosy. Indian J Lepr 1994;66:435-42.

16. Bhatia AS, Katoch K, Narayanan RB, Ramu G, Mukherjee A, lavania RK. Clinical and histopathological correlation in the of leprosy. Int J Lepr and Other Mycobact Dis 1993;61:433-8.

17. Sehgal VN, Rege VL, Reys M. Correlation between clinical and histopathologic classification in leprosy. Int $\mathrm{J}$ Lepr and Other Mycobact Dis 1977;45:278-80.

18. Kalla G, Salodkar A, Kachhawa D. Clinical and histopathological correlation in leprosy. Int $\mathrm{J}$ Lepr and Other Mycobact Dis 
2000;68:184-5.

19. Nadkarni NS, Rege VL. Significance of histopathological classification in leprosy. Ind J Lepr 1999;71:325-32.

20. Shenoi SD, Siddappa K. Correlation of clinical and histopathologic features in untreated macular lesions of leprosy- a study of 100 cases. Ind J Lepr 1988;60:202-6.

21. Cree IA, Smith WC, Beck JS. A quantitative study of relationship between systemic and histological parameters in immunity in individual leprosy patients. Int $\mathrm{J}$ Lepr other mycobact Dis 1990;58:347-52.

22. Bal A, Mohan H, Dhami GP. Infectious granulomatous dermatitis: A clinicopathological study. Indian J Dermatol 2006;51:217-20.
23. Bhusan P, Sardana K, Koranne R.V, Choudhary M, Manjul P. Diagnosing multibacillary leprosy: Acomparative evaluation of diagnostic accuracy of slit- skin smear, bacterial index of granuloma and WHO operational classification. Ind J Dermatol Venereol Leprol 2008;74:322-6

24. Groenen G, Saha NG, Rashid MA, Hamid MA, Pattyn SR. Classification of leprosy cases under field conditions in Bangladesh: I. Usefulness of skin smear examinations. Lepr Rev 1995;66:126-33.

25. Suneetha S, Arunthathi S, Chandi S, Kurian N, Chacko CJ. Histological studies in primary neuritic leprosy changes in apparently normal skin. Lepr Rev 1998;69:351-7. 